\title{
Fund i forskning
} ter som vigtige fund $\mathrm{i}$ deres forskning. $\mathrm{Vi}$ har bedt dem fremhæve ét. Vi bringer her en metodologisk pointering af Dorte Kousholt, et empirisk-analytisk fund af $\mathrm{Ann}-\mathrm{Ca}$ rita Evaldsson og en teoretisk-analytisk refleksion af Tuula Gordon.

Dorte Kousholt er cand.psych. og ph.d.stipendiat på Roskilde Universitetscenter, hvor hun er ved at færdiggøre sin afhandling om børns opfattelser af familieliv.

Ann-Carita Evaldsson er lektor ved Tema kommunikation, på universitetet i Linköping, Sverige, hvor hun arbejder med længerevarende etnografiske feltarbejder i kombination med konversationsanalyse.

Tuula Gordon er deputy director of Helsinki Collegium for Advanced Studies ved universitet i Helsinki, hvor hun arbejder med uddannelsessociologi og kønsstudier.

Teksten med Tuula Gordon er blevet til som en e-mailkorrrespondance. 


\section{Hvad jeg lærte om forskning i min sovepose...}

\author{
Af Dorte Kousholt
}

\section{0}

om led i forskningsprojektet "Familieliv fra et børneperspektiv" gennemførte jeg nogle såkaldte døgnobservationer, hvor jeg fulgte seks børns hverdag i 24 timer. De følgende sider har til hensigt at give et indblik i mine overvejelser over baggrunden for disse døgnobservationer - hvad jeg vovede metodisk og vandt empirisk.

\section{ET METODISK EKSPERIMENT}

I omtalte forskningsprojekt er jeg optaget af familieliv set fra børnenes ståsted. ${ }^{1}$ Jeg er optaget af familiens betydninger for børnene - ikke alene inden for hjemmets fire vægge, men også dens betydninger for børnenes liv andre steder. Hvad betyder familien for børnenes hverdag i børnehaven? Jeg havde en ambition om at komme txt på børnenes forestillinger, oplevelser og engagementer - og jeg ville forske gennem deltagelse i børnenes hverdagsliv. Jeg lavede deltagerobservation i børnehaven og interview med børn og forældre. Så langt så godt. Men mine ambitioner om at etablere et børneperspektiv i såvel forskningsdesign som analyser, kaldte på at tage et skridt videre. Jeg ville gerne observere børnene derhjemme. Deraf opstod ideen om at følge børnene en almindelig hverdag fra de stod op om morgenen til de gik i seng om aftenen. Jeg tænkte det som et metodisk eksperiment. Kunne det lade sig gøre, og hvad ville jeg få ud af det? Det var ikke en metode, jeg kunne læse om andre steder, og det var en overskridelse af den forsker- position, jeg kendte. Det kom til at foregå på den måde, at jeg var sammen med barnet $\mathrm{i}$ børnehaven, fulgte med når barnet blev hentet, legede, spiste aftensmad, hørte godnathistorie og fulgte med i hvad der ellers fandt sted af dagligdags begivenheder og rutiner. Sov ved siden af barnet til næste dag og fulgte med i børnehave igen.

$\mathrm{Da}$ jeg fremlagde min ide omkring døgnobservationer for forskerkollegaer og for pædagogerne i børnehaven mødte jeg interesse, men også stor skepsis i forhold til om familierne ville være med. Blandt de forældre og børn jeg inviterede til at være med i projektet mødte jeg interesse og åbenhed - især børnene var begejstrede for, at jeg skulle 'med hjem og lege'. Jeg foreslog forældrene, at de tænkte om mit besøg ligesom, når de havde en af børnenes kammerater fra børnehaven med hjem. Det fungerede som et konkret billede på den uvante situation, der bevægede fokus væk fra en kontrollerende forsker hen mod en nysgerrig gæst. Når det kunne lade sig gøre hænger det utvivlsomt sammen med den relation, jeg forinden havde opbygget til børn og forældre gennem min deltagelse i børnenes liv i børnehaven i over et år. Jeg var en velkendt person for børnene og ikke ukendt for forældrene.

\section{FORSKERPOSITIONEN VRIDES}

Børnene havde i børnehaven lært mig at kende som en voksen, der ikke intervenerede i deres indbyrdes konflikter eller på anden måde regulerede deres opførsel, en voksen der var interesseret i, hvad børn er optaget af og som gerne ville være med til at lege. ${ }^{2}$

Jeg var interesseret $i$ at se og opleve hverdagen i børnehaven og familien fra børnenes position i den. Derfor valgte jeg, så vidt muligt, at følge børnenes bevægelser og de regler og retningslinjer, der regulerede deres hverdag. Jeg forsøgte mig med i perioder at gøre som dem og ikke mindst sammen med dem og på den måde lare af, 
hvad børnene gjorde og deres intentioner med det. Det indebar nødvendigvis, at jeg afstod fra visse aspekter af voksenpositionens naturaliserede magt og rettigheder. Det skal hverken ses som et forsøg på at eliminere forskellene mellem barn og voksen eller at opføre sig som et barn. Det er en forskningsstrategisk positionering med det formål at åbne op for deltagelse og indsigt $\mathrm{i}$ børnenes hverdag. En sådan positionering på tværs af eller 'skævt' i forhold til de allerede etablerede positioner i praksis fandt jeg velegnet til at tydeliggøre naturaliserede forventninger til og forestillinger om kategorielle forskelle mellem børn og voksne, netop fordi man som voksen mødes af forventninger om at reagere genkendeligt $\mathrm{fx}$ at opretholde orden. Det er en ny position, der skal etableres, og det er man som forsker ikke alene om; den forhandles i samspil med den konkrete praksis, man deltager i. Over tid vænnede børnene sig til min måde at være til stede på; de holdt op med at regne mig for voksen, der kunne bestemme eller irettesætte og begyndte at relatere til mig mere som en ligeværdig deltager. Jeg blev inddraget i lege og fælles aktiviteter, og jeg oplevede flere gange at børnene antog, at de regler som gjaldt for dem også gjaldt for mig. Fx at man skulle spørge om lov til at gå indenfor.

Det var denne forudgående relation til børnene, der var døgnobservationernes bærende element. For børnene var jeg 'den samme' - en lidt 'anderledes voksen'. Eller mere præcist: visse aspekter af min 'voksenhed' forblev i baggrunden, da de ikke var relevante for relationen mellem os. Børnene greb $\min$ tilstedeværelse forskelligt som de også havde gjort det i børnehaven. For nogle af børnene var det muligheden for at få en legekammerat med hjem, der fremstod tydeligst. For andre var jeg mere en gest af familien. Det var deres opfordringer og invitationer til, hvad vi skulle lave, der var med til at forme min tilstedeværelse i hjemmet. Men positionen som deltagende observatør forandrede sig i overgangen fra børnehave til hjem - i kraft af at vi havde skiftet sted: Jeg var selv mere anspændt, selvrefleksiv og optaget af at falde ind på den rigtige måde. Det minder mig om oplevelser fra jeg selv var barn, af at være på besøg hos en ven eller venindes forældre for første gang. Det billede, jeg havde præsenteret for forældrene, omkring 'at tage en kammerat med hjem' kom også til at fungere som en ramme for min egen oplevelse.

Døgnobservationerne skærpede mit blik på mig selv som forsker. På min position, det jeg gjorde og hvordan jeg kunne og skulle være til stede i feltet. Bevægelsen ind i og tættere på børnenes og familiernes liv blev dermed også en udforskning og udfordring af forskningsfeltet og forskerens egne præmisser. Døgnobservationerne bragte mig tættere på børnene og familiernes hverdag, men bragte også dem tættere på mig - eller forskningen tættere på forskersubjektet. Børnene involverede mig i deres liv, og jeg lærte af at lade mig involvere. Men de bragte mig også jævnligt på usikker grund. Det var en personlig udfordring; berigende og udmattende på samme tid. Døgnobservationerne var 24 timers intens selvrefleksiv tilstedeværelse: En samtidig medleven og distanceret opmærksomhed.

\section{HVAD JEG VANDT EMPIRISK}

Gennem min deltagelse i børnenes hverdag i børnehaven havde vi lært hinanden at kende. Vi havde delt oplevelser og fået erfaringer om og med hinanden. Døgnobservationerne fungerede på denne måde som en udvikling af et allerede etableret bekendtskab og som en del af et forløb: Når vi ankom sammen til børnehaven den næste dag, havde vi noget mere sammen, vi havde delt oplevelser udenfor børnehavens regi og udvidet vores frelles erfaringer og kendskab til hinanden.

Døgnobservationerne gav et indtryk af, hvordan hjemmet konkret bruges, og hvordan hverdagen organiseres spatialt. Hvilke 
familiemedlemmer befinder sig hvor og hvad laver de der? Døgnobservationerne gav mulighed for at følge børn og forældres måder at deltage på, handlingers konkrete fremtrædelse, kropslige og verbale udtryk og dialoger og konkrete samspil. Jeg fik et indblik $\mathrm{i}$ praktiske organiseringer af hverdagssituationer fx aftensmåltid, sengelægning, opvågning, morgenmad m.m. Jeg fik mulighed for at danne mig indtryk, fornemmelser og opleve stemninger. Døgnobservationerne gav nogle gange kød og blod til situationer eller konflikter, som jeg forinden havde talt med forældre eller børn om i interviews. Det gav mulighed for at spørge til det, jeg kunne se. Døgnobservationerne udvidede og supplerede den viden om familiens dagligdag, jeg havde fået gennem interview med hhv. børn og forældre, og gav mig mulighed for at bringe de forskellige typer af viden i spil sammen i analyserne.

Det metodiske eksperiment jeg satte i gang, og den empiri der kom ud af det, blev en central del af forskningsprojektet. På én og samme tid blev det, det vigtigste jeg gjorde, og noget der kun får sin berettigelse gennem det andet, jeg også gjorde. Mit kendskab til børnene, deres måde at inddrage mig på i deres hverdag, samt vores indbyrdes relation kom til at fungere som væsentlige rettesnore i mine analyser.

Det jeg tager med mig videre på min forskerfærd er først og fremmest det bidrag, døgnobservationerne har ydet til mine empiriske analyser. Men oplevelsen af at have overskredet egne og andre forskeres grænser er også værd at have med og giver lyst til nye udfordringer.

\section{NoTER}

1. Forskningsprojektet beskrives i Kousholt, D. (in prep): Familieliv fra et borneperspektiv. Deltagelse $i$ follesskaber. Ph.d. afhandling, Roskilde Universitetscenter

2. Min position som deltagerobservatør er inspireret af etnografisk feltarbejde blandt børn (bl.a Corsaro 1985, Davies 1989, Thorne 1993). Samt diskussioner inden for børneforskningen omkring "the least adult role" (bl.a. Epstein 1998, Mandell 1991); diskussioner om positioneret deltagelse (ex. Hasse 2000) og embodied knowledge (Okely 1992).

\section{LITTERATUR}

. Corsaro, W.A. (1985): Friendship and Peer Culture in the early years. Norwood, Ablex Publishing, NJ.

- Davies, B. (1989): Frogs and snails and Feminist tails. Allen \& Unwin Pty Ltd.

- Epstein (1998): “Are you a girl or a teacher? The 'Least Adult' Role in Research about Gender and Sexuality in a Primary School”. In: Walford, G. (ed.): Doing Research about Education. Falmer Press.

- Hasse, C. (2000): Overvejelser om positioneret deltager-observation. Sexede astronomer og kønnede læreprocesser. I: Kvinder, Køn og Forshning, 9. årgang nr. 4., s. 39-51.

- Mandell (1991): "The Least-Adult role in Studying Children”. In: Waksler, F.C. (ed.): Studying the social worlds of children: sociological readings. Falmer Press.

. Okely J. (1992). “Anthropology and autobiography. Participatory experience and embodied knowledge". In: Okely, J. and Callaway, H. (eds.): Anthropology and autobiography. Routledge, London.

- Thorne, B. (1993): Gender Play: Boys and Girls in School. University Press, Buckingham. 
Skiftande identiteter och könsvarationer $\mathrm{i}$ yngre skolbarns samspel med kamrater

\author{
Af Ann-Carita Evaldsson
}

$\mathrm{D}$ en här metodologiska betraktelsen utgår från egna och andras erfarenheter av att studera yngre skolbarns vardagliga samspel i skilda sociokulturella sammanhang (för en översikt se Corsaro 1997, Goodwin 1990, Kyratzis 2004, Thorne 1993). Studierna lyfter fram betydelsen av att i detalj studera hur barn förhandlar sociala relationer och identiteter i vardagligt samspel med kamrater. Influenser hämtas framförallt från etnometodologi med intresse för medlemmars meningsskapande processer, konversationsanalys med fokus på tal som social organisation och Goffmans mikrosociologi, men även lingvistisk antropologi och sociolingvistik. Centrala antaganden är att barn och kamratkulturer är aktiva socialisations agenter och att språk (i.e. vardagligt tal) är sociala handlingar med vilkas hjälp barn konstruerar sin sociala verklighet. I samspel med kamrater omskapar barn relationer, språk och identiteter samtidigt som de etablerar kamratkulturer, vilka både tar upp värderingar från vuxenvärlden och utmanar densamma.

I linje med den syn på genus som utmärker dagens genusstudier är studiet av barns samspel och kamratkulturer genomsyrat av en social konstruktivistisk och performativ syn på genus (för en översikt se Kyratzis, 2001; Thorne 1993). I fokus är hur sociala identiteter som genus, klass, etnicitet, ålder, etc. förhandlas och etableras i barns interaktion i rutinaktiviteter med kamrater. En förutsättning för att $\mathrm{i}$ detalj studera hur barn etablerar relationer, språk och identiteter i vardagligt samspel med kamrater är användning av audio- och/eller videoinspelningar i kombination med etnografi. Jag kommer fortsättningsvis att visa hur konversationsanalys i kombination med etnografi kan användas för att i detalj utforska yngre skolbarns i samspel och identitetsarbete på skolgården. Av utrymmesskäl är beskrivning av skola, elevers etniska bakgrunder, kamratgrupper, språkbruk, lekar och spel på skolgården, etc. begränsad.

\section{SKIFTANDE IDENTITETER I FLICKORS (OCH POJKARS) BOLLSPEL PÅ SKOLGÅRDEN}

Under en period av ett år dokumenterade jag mellanstadieelevers samspel (20 tim. video och 200 tim. audio), i olika klasser från fyran till sexan, i en mångkulturell skola $\mathrm{i}$ Sverige. En kamratgrupp av 8 st 11 -åriga flickor (och 6 st pojkar) i femte klass, med olika etniska bakgrunder (syriansk, kurdisk, chilensk och svensk), spelade dagligen boll på uppritade fyrkanter ("rutan") på skolgården (Evaldsson 2003, 2004). På så vis etablerade flickorna delvis tillsammans med pojkarna en kamratkultur som överskred etniska och könsmässiga gränser där umgänge med klasskamrater, fysisk skicklighet och att behärska spelet var centralt. Tvärtemot studier av könsskillnader, vilka tenderar att reproducera närmast givna, statiska, enhetliga och separata könskategorier (för en kritik se Thorne 1993, 89-110) ägnade sig flickorna åt fysiska aktiviteter, tog upp plats, etablerade hierarkier, och tävlade med varandra.

Genom att jag i detalj analyserade flickornas samspel med utgångspunkt $i$ videoinspelningar av spelet blev de interaktiva resurser som flickorna använde för att kontrollera spelet tydliga. I exemplet nedan vi- 
sar Marion med emfatisk ton, förhöjd röst, anklagelser, berättiganden och pekningar att Sonya missat bollen och skall lämna rutan.

\section{EXEMPEL 1}

1. Sonya: ((stannar i rutan $))$

2. Marion: $\mathrm{DE} \mathrm{E} \neq \mathrm{D} \underline{\mathrm{U}}$ SOM GICK $\neq \underline{\mathrm{UT}}$ !

3. $\quad($ tar ett steg in i S's ruta och pekar med armen))

5. Marion: DE KọM I DIN RUTA I[FF $\underline{\mathrm{O}} \mathrm{R} S T !]$

6. ((pekar på marken $))$

7. Sarah: $\quad$ J $\underline{O}::$ ] den kom $\neq$ hit å sen $\neq$ dit

8. ( (tar ett steg framåt och pekarpå marken ))

9. Sonya: ((lämnar rutan och ställer sig utanför fyrkanten))

Ovanstående är ett av många exempel jag har på hur flickor med fysisk skicklighet $\mathrm{i}$ att kasta boll använder en rad interaktiva resurser (tillrättavisningar, anklagelser, berättiganden, explicita invändningar, förhöjd röst, markerade gester) för att kontrollera och definiera spelets regler (se också Goodwin 1998, 2002). Utan att tveka ställer de flickor som behärskar spelet varandra till svars för regelbrott och deltar i utdragna dispyter för att definiera spelets regler och utgång. Snarare än att upplösa spelet vid konflikter vilket enligt Lever (1976) med flera är vanligt i flickors lekar fortsätter de spela. I motsats till den 'moraliska ordning av omsorg' som enligt Brown \& Gilligan (1992) kännetecknar flickor i allmänhet, orienterar sig flickor som behärskar spelet mot en 'moralisk ordning av rättvisa', vilken annars tillskrivs pojkar som grupp.

Parallellt som flickorna etablerar sociala hierarkier och status i spelet samarbetar de med varandra. I exempel I linje 7-8 understödjer Sarah Marion genom att invända mot Sonya och peka i hennes ruta. Det antyder i sin tur att fenomen som konkurrens och samarbete inte går att skilja och ej kan tillskrivas pojkar respektive flickor var för sig som grupp. Nästa utdrag visar hur samma flickor i samspel med flickor som inte fysiskt behärskar spelet tonar ner fysisk skicklighet, ursäktar sig och tar ansvar för andra.

\section{EXEMPEL 2}

26. Anna: ((missar bollen, lämnar rutan $))$

27. Marion: förlåt, förlåt ((vänder sig runt, ler förläget))

29. Sonya: ja tar in dig sen. Du, Carla å Anki

Genom att skifta beteende i interaktion med flickor som inte behärskar spelet orienterar sig samma flickor som tidigare nu istället mot en 'moralisk ordning av omsorg', vilken enligt Gilligan mfl anses känneteckna flickor. En moralisk ordning av omsorg upprätthålls genom att flickorna använder 'tjejkast', ursäkter, indirekta tillsägelser, fniss och mjuk röst, fysiska och språkliga repertoarer som vanligtvis tillskrivs flickor (Coates, 1996). På samma vis skiftar flickorna spelstil i spel som 'tjejerna mot killarna'. I exempel 3 spelar Marion och Sarah mot Sherbel och William.

\section{EXEMPEL 3}

1. Sherbel: NÄ::! DU ! ja får göra boxnin-

2. ((studsar bollen, börjar kasta))

3. Marion: N $\underline{\ddot{A}}::$ tjejerna făr inte!

4. Sherbel: du făr inte göra så här!

((visar Marions kast))

okej!

6. Marion: jof:

7. Sherbel: de e samma sak! $\neq$ J्O !

8. Marion. NÄ̈::!

9. Sherbel: varför får man inte göra något annat?

10. ((studsar bollen, som träffar hans fot))

11. Sarah: du gick ut

12. Sherbel: ja gick inte ut (.) ja skulle gö- man får göra boxningar

13. Marion: du kommer ändå inte att ta ut mig (.) ja tar ut dig! 
De två flickorna kontrollerar inte bara spelets regler och pojkarnas fysiska handlingar utan utmanar också dem. När William utanför excerpten missar bollen skrattar både flickorna och pojkarna. I 'tjejerna mot killarna' skämtar flickor med pojkar och deltagarna kan sägas orientera sig mot en 'moralisk ordning av lekfullhet' (Evaldsson 2004). Medan andra forskare menar att flickor och pojkar i spel med motsatta könsgrupperingar förstärker könsgränser (sk. "border-work" se Thorne 1993, 64-88) visar min analys att deltagarna lekfullt prövar och omprövar könsstereotypier. Generellt genomsyras 'tjejerna mot killarna' av att de flickor som behärskar spelet har en större tolerans för lekfullhet, skratt och omförhandlingar av regler, än när de spelar själva. Att flickorna i mina exempel skiftar interaktiv repertoar när spelarna skiftar understryker att flickor som grupp inte kan tillskrivas ett enhetligt homogent och separat beteende.

\section{KONVERSATIONSANALYS OCH ETNOGRAFI I STUDIER AV GENUS OCH KAMRATGRUPPSSAMSPEL}

Jag skall avslutningsvis reflektera över betydelsen av att använda konversationanalys i kombination med etnografi för att utforska yngre skolbarns identitetsskapande med fokus på genus. Om vi utgår från att genus konstrueras i barns deltagande i vardagliga aktiviteter blir det också viktigt att dokumentera och i detalj analysera barn aktiviteter med kamrater i skilda sammanhang. Etnografi som metod ger möjlighet att studera andra grupper av flickor, dvs. med minoritets- och låginkomstbakgrund (se framförallt Goodwin 1990, 1998), än enbart flickor med medelklass bakgrund. Det blir också möjligt att visa på skolsammanhangets betydelse. Exempelvis kan flickornas skifte av identiteter och repertoarer $\mathrm{i}$ mina exempel förstås mot bakgrund av skolans regel om att 'alla få vara med', elever skall samarbeta oberoende av kön och att både flickor och pojkar har tillgång till sportaktiviteter.

Genom att delta över en längre period i elevers skolvardag och dokumentera aktiviteter i olika kamratgrupper fick jag syn på variationer mellan skilda flickgrupper. Det var dock först vid en detaljerad konversationsanalys av inspelningarna, baserad på upprepade genomlyssningar, som jag fick syn på hur deltagare i en och samma grupp skiftade positioner, identiteter och repertoarer. Även bland flickor i grupper i intima smågrupper skiftade deltagarna positioner. Tydliga hierarkier och utdragna dispyter riktade mot enskilda flickor förekom parallellt med förmildrande och understödjande tal (Evaldsson 2005 ms). Detaljanalyser visar att flickorna använder en rad språkliga och fysiska repertoarer som vanligtvis inte tillskrivs flickor (se också Goodwin 1998, 2002). Att flickor skiftar identiteter, repertoarer och positioner i interaktion med kamrater gör det svårt att utgå från närmast universella och binära positioner, som att flickor är 'på ett visst sätt' och pojkar 'på ett annat'. Förslagsvis bör vi överge frågan 'hur skiljer sig pojkars och flickors aktiviteter åt? och istället utforska variationer mellan och inom flick- och pojkgrupper så som de uttrycks i barns interaktion i vardagliga aktiviteter med kamrater i skilda sammanhang.

\section{LITTERATUR}

- Coates, J. (1996): Women Talk: Conversations between Women Friends. MA: Blackwell, Cambridge. . Corsaro, William (1997): The Sociology of Childhood. Pine Forge Press, Thousand Oaks.

· Brown, L.M. \& Gilligan C. (1992): "Meeting at the Crossroads: Women's Psychology and Girls' Development". MA: Cambridge University Press, Cambridge.

- Eder, D. (1995): School Talk. Gender and Adolescent Culture. Rutgers University Press, New Jersey.

. Evaldsson, A-C. (2002). “Boys' gossip telling: Staging identities and indexing (unacceptable) masculine behaviour", Text, 22 (2), 1-27. 


\section{Tuula Gordon: Wallflowers?'}

Temaredaktionen: If you were to point to a particular finding that has altered your way of thinking or changed your way of conducting research, what would it be?

Tumla Gordon: Your question started a train of thought concerning the concept of agency but to cut the thoughts a little short, let me tell you about the 'wallflowers' and how I use 'Dancefloor' as a metaphor of dynamic working out social relations in space and time, and how I find it indeed important, challenging and productive. The metaphors draw attention to the materiality of social relations, and their locatedness in space. It refers to marginalisation in processes of interaction. This marginalisation may be something chosen, because it provides safety in the circumstances. Entering the dancefloor may mean that one is exposed to unexpected events. Or the marginalisation may be enforced by other people who occupy the centre stage and control access to that space.

The metaphor of a 'wall flower' points out that in spatial embodied relations girls are more likely to be in the margins than boys. This does not mean that gender is an absolute category - boys may be off the centre too, but culturally we have no equivalent well recognized metaphor for this. Quiet boys may then have a particularly hard time, because they are on the margins of social relations based on powerful masculinities.

Temaredaktionen: Have you pursued the quiet boys and their possibilities of altering their position? Or how has this finding influenced your research? And would you say that the fact that a culturally acknowledged metaphor of wallflowers put a gender divi- 
sion as to whom can be acquired, so that girls are easily acquired by the metaphor means that they are left with less possibilities of doing differently?

Tuula Gordon: It is interesting that 'wallflowers' is such a gendered expression attributing marginality to girls. We [Tuulua Gordon worked with Janet Holland and Elina Lahelma] wanted to problematise that by asking 'who are the wallflowers'. Marginality is an important theoretical concept, but working out its implications when addressing empirical data is complicated.

We are studying what and not who are marginalised. Therefore we also challenge the idea of boys faring badly at school. Many boys do well in school. They can do the right steps and they want to do them. But at the same time we must emphasise the diversity of boys - and suggest that 'boys doing badly' discourse does not address quiet boys who move in the margins. Some of the boys who are not achieving well in the official school - who don't do the right steps there - may be good at improvising new and different steps, and their abilities may be much appreciated by others.

But indeed the quiet boys may have problems. Indeed, although I agree with your suggestion that quiet girls may have less possibilities for doing things differently, I will add that they may find protection in their silence. They may be dreaming about their possibilities, and manage to keep those dreams to themselves - and therefore they can endeavour to grasp their dreams. At this point I have been influenced for example by bell hooks and Valerie Walkerdine, although I see more possibilities for agency in silence. Whilst 'talking back' (hooks) is necessary in order to construct a voice that can be enunciated and heard (Walkerdine), quiet dreaming may be a space of protection that provides a position that facilitates agency.
Quiet boys do not fit into conceptions prevalent about boys, and often those who bemoan the position of boys in schools completely forget these quiet boys. Their agency may be further curtailed by some of the debates on boys at school. Although I must add that there is some evidence in our data that some boys do use silence as a form of protection too, and they may exercise quiet agency as well.

Generally, I think agency is a crucial concept. Furthermore I think it is crucial not only to look at how agency is 'visibly' exercised. What is equally important is a sense of agency, a sense of an 'I' that make decisions. It is important to be able to act, but it is also important to think that you can and you will - even if there are no visible signs of it at that moment.

Crucial for us has been a statement by Giddens: he suggests that every limitation is an opportunity for enactment.

But whilst it would be nice to conclude on the basis of that agentic notion, I must add that of course (some) young people encounter increasing difficulties when they endeavour to exercise their agency. These increasing difficulties are constructed in the context of new right politics. Neo-liberalism emphasises the opportunities and responsibilities of individuals, and in that talk the differential restrictions and obstacles experienced by some of them are suppressed and ignored. Power is made invisible in individualistic talk. So finally I want to emphasise the importance of the notion of a welfare society that has been constructed in Nordic countries. And I use the concept of welfare society rather than welfare state purposefully. Through notions of citizenship that emphasise common struggles for equity a more just society can be strived for.

\section{Note}

1. 'wallflower' betyder 'bænkevarmer' 